\title{
Urodimento
}

REVISTA DE ESTUDOS EM ARTES CÊNICAS

E-ISSN 2358.6958

\section{A leitura do pedestre-espectador ou um corpo em meio à transitoriedade}

\author{
Cecília Lauritzen Jácome Campos
}

Para citar este artigo:

CAMPOS, Cecília Lauritzen Jácome. A leitura do pedestreespectador ou um corpo em meio à transitoriedade. Urdimento - Revista de Estudos em Artes Cênicas, Florianópolis, v. 2, n. 41, set. 2021.

doi DOI: http:/dx.doi.org/10.5965/1414573102412021e0202

Este artigo passou pelo Plagiarism Detection Software | iThenticate 


\title{
A leitura do pedestre-espectador ou um corpo em meio à transitoriedade ${ }^{1}$
}

Cecília Lauritzen Jácome Campos²

\section{Resumo}

O texto percorre três experiências distintas (como espectadora, performer e pesquisadora) de aproximação com manifestações cênicas de cunho performativo no espaço urbano. Em diálogo com os relatos o texto expõe diversas abordagens dos aspectos espaciais que envolvem o acontecimento teatral performativo urbano, propõe o esboço de uma certa cartografia do pedestre-espectador e reflete acerca da leitura resultante da relação que os espetáculos de rua estabelecem com seu público.

Palavras-chave: Teatro performativo. Recepção. Espectador. Espaço urbano.

\section{The pedestrian-spectator reading or a body amid transience}

\begin{abstract}
The text goes through three distinct experiences (as spectator, performer and researcher) with scenic manifestations of performative nature in the urban space. In dialogue with the reports, the text exposes various approaches to spatial aspects that involve the urban performative theatrical event, proposes the outline of a certain cartography of the pedestrian-spectator and reflects on the resulting reading of the relationship that street spectacles establish with their audience.
\end{abstract}

Keywords: Performative theater. Reception. Spectator. Urban space.

La lectura del peatón-espectador o un cuerpo en medio de la transitoriedad

\section{Resumen}

El texto pasa por tres experiencias distintas (como espectadora, performer e investigadora) de aproximación con manifestaciones escénicas de carácter performativo en el espacio urbano. En diálogo con los reportajes, el texto expone varias aproximaciones a los aspectos espaciales que envuelven el evento teatral performativo urbano, propone el trazo de una determinada cartografía del peatónespectador y reflexiona sobre la lectura resultante de la relación que los espectáculos callejeros establecen con su audiencia.

Palabras clave: Teatro performativo. Recepción. Espectador. Espacio urbano.

${ }^{1}$ Este artigo foi elaborado a partir de minha tese de doutorado intitulada A recepção acidental: vias de leitura do teatro performativo defendida no Programa de Pós-Graduação em Teatro (PPGT) da Universidade do Estado de Santa Catarina (UDESC) concluído no ano de 2018, sob orientação do Prof. Dr. Flávio Augusto Desgranges de Carvalho e com os apoios do Programa de Bolsas de Monitoria de Pós-Graduação (PROMOPUDESC) e da Coordenação de Aperfeiçoamento de Pessoal de Nível Superior (CAPES).

2 Doutora em Teatro pela Universidade do Estado de Santa Catarina (2018). Professora Assistente do Curso de Licenciatura em Teatro da Universidade Regional do Cariri (URCA). ceci.lauritzen@gmail.com

(9) http://lattes.cnpq.br/1380951722577052

(iD) https://orcid.org/0000-0002-0032-2849 


\section{Vertigem: A última palavra é a penúltima - 2.0}

Começo pelo relato de uma vivência ${ }^{3}$, porque se relaciona de modo muito próximo com as dimensões do real propostas pela cena performativa, engajando o público de diversos modos na ação cênica. O espetáculo A última palavra é a penúltima - 2.0 aconteceu à noite numa passagem subterrânea no centro da cidade de São Paulo, onde os espectadores eram alocados em pequenas cabines disfarçadas de vitrines. A escolha do espaço ocupado pelo Teatro da Vertigem foi decisiva na configuração de uma experiência do real ${ }^{5}$, à medida que incorporou os fluxos da cidade deixando a cena permeável aos acontecimentos cotidianos. Esta característica de troca permanente com o espaço revelou-se como um recurso valioso na aposta da produção de certa disponibilidade do público. "Em A última palavra é a penúltima - 2.0 pude me aproximar das percepções sutis da cena performativa; seus efeitos reverberam como faíscas de um acontecimento real, permeado de traços surreais, ficcionais, bem como do campo da dúvida" (Campos, 2016, p. 68). Cabe ressaltar que o teor extremamente inóspito do espaço em que o espetáculo se desenvolveu na maioria do tempo gerou nos espectadores uma qualidade de participação que escapa a qualquer possibilidade de mise-en-scène em detrimento da convenção teatral.

De certa forma, é possível mapear três lugares em que o público se encontra durante A última palavra é a penúltima - 2.0. O primeiro lugar que considero o principal é constituído pelas galerias laterais à passarela, para onde os espectadores foram conduzidos no início do espetáculo. Desse lugar é possível experienciar o evento através de vidros, como se estivéssemos em uma vitrine. Dependendo do jogo com as luzes e os vídeos projetados, conseguimos enxergar a cena do lado de fora, o público na vitrine oposta ou apenas a cabine em que estamos com as pessoas ao lado. O fato de sabermos que também estamos

\footnotetext{
${ }^{3}$ Desenvolvi esta discussão em outro momento, de modo mais aprofundado, no artigo: Campos, 2016.

${ }^{4}$ O espetáculo foi assistido em dezembro de 2014 durante a 31ạ Bienal, com direção de Antônio Araújo e Eliana Monteiro, inspira-se no texto de Gilles Deleuze, o esgotado.

${ }^{5}$ A principal justificativa para a relação que faço localiza-se no fato de que a passagem subterrânea não foi interditada para o espetáculo acontecer, ou seja, havia um trânsito natural de pedestres que se utilizava do espaço, enquanto o recorte feito pelos espectadores "escondidos" nas cabines era de um espetáculo em andamento.
} 
sendo vistos, por atores e por espectadores (acidentais) que percorrem a galeria instaura uma qualidade de presença distinta daquela que experimentamos enquanto público quando estamos, de certa forma, protegidos no escuro, apenas usufruindo da intimidade da nossa leitura. Nesse sentido, Féral (2008, p. 209) apresenta como a performatividade evidencia-se no processo da atuação e aborda igualmente o papel do espectador, defendendo a instauração de uma "estética da presença", ou seja, um engajamento em que "a atenção do espectador se coloca na execução do gesto, na criação da forma, na dissolução dos signos e em sua reconstrução permanente". Estar no espaço configura uma participação. O espectador é inserido nesse espaço de expectativa ampliada e constante suspensão "entre o ver a cena e os espectadores do outro lado do corredor e o ser visto por ambos; efeito possibilitado pela estrutura das vitrines montadas nas galerias da passagem subterrânea" (Campos, 2016, p. 68).

O segundo lugar onde o público pode reunir-se é na própria rua, pois em alguns momentos há cenas, bem como trocas de roupa, acima da passagem subterrânea e nas escadas. Tais cenas são projetadas para o público da galeria por meio de um telão instalado próximo às escadas. O terceiro lugar, mais difícil de localizar em termos espaciais, abarca a parcela do público flutuante/acidental que constituía a cena enquanto transitava pela passarela, confundindo-se por vezes com os próprios atores. A experiência em A última palavra é a penúltima - 2.0 é fértil no contexto atual, pois além de contribuir para a reflexão sobre o fenômeno da recepção acidental, me leva a refletir sobre as configurações espaciais que um espetáculo teatral na rua pode assumir e como estas influenciam na ideia de um posicionamento mais ativo do público (Campos, 2016). A partir dessa alteração na atitude do espectador, não é apenas a relação com o espetáculo que é abalada, mas, em alguma medida, a do sujeito consigo mesmo, uma vez que o público é convidado a assistir-se; a "estar no mundo" (Oiticica, 1986).

\section{Nomear o sujeito-pedestre}

A partir do relato inicial feito, proponho, agora, uma aproximação dos aspectos espaciais que envolvem o acontecimento teatral performativo urbano e 
o esboço de uma certa cartografia do pedestre-espectador. Nesse quadro a leitura resultante da relação que os espetáculos de rua estabelecem com o público abarca o foco dessa discussão. A argumentação que guia o texto é a de que o teatro performativo urbano, pelas condições espaciais onde acontece e pela abordagem da cena com base na performatividade, convida a uma leitura e participação específicas, sendo necessário portanto pensarmos acerca do público, dialogando a partir das abordagens teóricas disponíveis. Pensar acerca do público do teatro feito na rua subentende não o localizar ou definir, no entanto o questionamento é pertinente: como nomear este sujeito-pedestre que é tomado de modo involuntário por um acontecimento teatral performativo na cidade? Como termos distintos como público, espectador, audiência, testemunha e participador podem contribuir para a discussão?

A noção de público é comumente abordada segundo sua composição sociocultural, a partir da qual são analisados aspectos relativos ao gosto e ao senso de apreciação. Com inspiração na psicologia experimental, segundo Pavis (2007), estes estudos utilizam-se de questionários como procedimento metodológico para chegar a dados que analisem tais aspectos. Nesse sentido, há uma relação constante e de fundamental importância entre os dados quantitativos e qualitativos no estudo do público teatral.

A jornalista e pesquisadora Beth Néspoli (2015) ao refletir ${ }^{6}$ sobre a parcela de espectadores que frequentou o espetáculo Bom Retiro 958 metros $^{7}$ durante sua temporada de acompanhamento, detectou dois grupos típicos de público que ela chamou de endógeno e exógeno. Conforme Néspoli (2015), o público endógeno seria aquele que de algum modo se encontra envolvido com o espetáculo desde sua gênese, por parentesco, amizade, simpatia e/ou admiração, representado por indivíduos tais como: "jornalistas da área de cultura, pesquisadores, críticos, diretores, atores, estudantes de teatro, amigos, parentes” (Néspoli, 2015, p. 132). O público exógeno, por sua vez, refere-se aos espectadores que não costumam frequentar o teatro ou não se encontram inseridos de qualquer modo com o meio

${ }^{6}$ A autora desenvolveu estas reflexões na tese intitulada Teatro da Vertigem: Construção Poética e Recepção. Estudo do campo de tensão que se instaura no encontro da proposição artística com seus receptores.

Este espetáculo foi uma produção do grupo paulistano Teatro da Vertigem, estreou no ano de 2012 e teve direção de Antônio Araújo e codireção de Eliana Monteiro. 
teatral. Seu estudo permite uma ampliação das vozes e dos olhares sobre a cena, incorporando sujeitos diversificados, de vínculos desconhecidos, múltiplas origens e motivações.

Néspoli (2015) observou a importância desse público exógeno na temporada de Bom Retiro 958 metros na medida em que tais espectadores apresentaram contribuições diferenciadas para a pesquisa que se desenvolvia e, consequentemente, para a produção de conhecimento da produção teatral contemporânea:

Tal aspecto de efemeridade reforça a importância de investigações que ampliem as vozes no campo de tensão em estudo por meio da escuta do público exógeno. Em geral, o que é legitimado como recepção crítica de um espetáculo é a análise de um somatório de textos e de depoimentos circunscritos àquela parcela de espectadores integrada por críticos, jornalistas culturais, pesquisadores universitários e estudantes de teatro que, dependendo do alcance e repercussão da temporada, pode ficar restrito a um grupo que partilha repertórios e critérios de análise muito similares no que diz respeito à linguagem teatral (Néspoli, 2015, p. 218).

A citação pontua a questão do padrão da recepção crítica de um espetáculo teatral, problematizando a própria noção de legitimidade que em geral fica reduzida a uma parcela de público especializado. Tal questionamento toma como base a própria constituição do público teatral, constatado pela autora como um público frequentemente endógeno, ou seja, formado no seio da criação cênica, abrangendo limites curtos no que tange a diversidade de indivíduos.

Por sua vez, no artigo Observatório do chão para cenas de rua Kil Abreu (2016) concentra-se na tentativa de pensar uma crítica ao teatro de rua na atualidade. Abreu (2016, s/p) usa o chão como metáfora condicional e ponto de partida para o olhar especializado e pergunta-se: "Que tipo de ruído ao ambiente uma cena de rua de base performativa causa? [...] Como observar diante de uma cena muitas vezes "sem centro"? Como definir as bordas do trabalho crítico diante de uma cena sem bordas?”.

Nesse contexto de estudo parto, primeiramente, da impossibilidade de delimitar um público específico. Segundo, sendo impossível certa delimitação as perguntas que surgem são: como olhar para tal "tipo" de recepção e o que 
configura o olhar do público que se constitui através do acidente? Em outras palavras, Abreu (2016, s/p) reforça a importância da inclusão da consideração do acidental para pensarmos o teatro contemporâneo de rua:

O que nos dizem os comentários dos espectadores, mesmo os que passam e não param? A tendência a termos uma paisagem humana mais diversa e menos estável modifica o olhar sobre a recepção? Em que medida a recepção, nestes termos, pode influenciar o juízo crítico? [...] Como considerar os lances acidentais, como olhar os pequenos dramas, fora do roteiro? Relações transitórias entre plateia e atores podem ser mais relevantes e transformadoras que a grande cena.

Por outro lado, por ser objeto de estudo de diversas áreas, dentre as quais estão a semiologia, a sociologia, a psicologia e a antropologia, o espectador se configura como noção complexa, inclusive por se estruturar em duas dimensões, uma individual e outra coletiva, tal seja àquela que compreende o público. Segundo Pavis (2007), a noção de espectador supera a visão de uma suposta unidade no coletivo, propondo a aceitação de uma individualidade que forma um corpo heterogêneo, porém que não perde seu caráter de coletividade. O autor problematiza o pensamento da estética da recepção, segundo o qual existiria um espectador implícito ou ideal, capaz de captar todas as intenções e concretizar os objetivos de uma encenação. Conforme Pavis (2007), o espectador do teatro, diferentemente do cinema, vive a convenção e é consciente dela, por isso, escolhe envolver-se, deixar-se levar, devanear ou não.

Tal visão do espectador como manipulador de suas próprias emoções pode ser relativizada, principalmente, quando nos referimos às experiências pensadas e propostas pelo teatro contemporâneo, em suas interseções com outras linguagens artísticas. Mesmo a cena que tem em seu cerne a noção de performatividade compartilhada entre artista e público não se conforma pela manipulação do espectador, porque a relação é o que configura o acontecimento. O que não ignora a autonomia como princípio de ação do espectador, em especial este do qual tratamos, tal seja o pedestre do espaço público que se desloca "livremente" pela cidade e pode se deparar com o acontecimento teatral, permitindo-se envolver ou não. 
O termo audiência pode ser somado ao debate, uma vez que faz referência à dimensão coletiva da recepção, cujo sentido remete diretamente à noção de escuta e a um certo espaço de recebimento, ao destino de uma mensagem. A noção de audiência faz associação, igualmente, a um corpo único, integral, similar, tal como presente na noção de público. Ao se debruçar sobre seu estudo, a professora e pesquisadora norte-americana Alice Rayner (1993) propõe outros olhares para o termo, sugerindo pensá-lo como um modelo/modo de relações intersubjetivas, opondo-se à conformação da comunidade homogênea. Ao analisar de modo aprofundado o termo audiência, Rayner (1993) sugere que a raiz do seu senso comum - o que fundamenta a crítica da autora - está no próprio ato ético de escutar, a partir do entendimento do que seja o ato de escuta. Nesse sentido, se a escuta é encarada como um ato passivo, de caráter fixo, rígido e imóvel, assim também será vista a audiência, ou seja, a parcela de sujeitos que reunidos praticam o ato de escutar.

Diante de tal realidade, Rayner (1993) enxerga como uma armadilha o fato de pensarmos a audiência ou o público como uma configuração estável, principalmente quando nos referimos a ela como uma união das diferenças num mesmo corpo. A autora aponta, igualmente, para o que a palavra audiência implica, para uma determinada divisão entre quem fala e quem escuta, ou quem realiza e quem observa. Contrapondo-se a este pensamento, Rayner (1993) sugere refletir acerca de uma condição fronteiriça que seria genuína da audiência, porque põe um sujeito em confronto com o modo de pensar do outro, na busca por entender as contradições presentes nas próprias diferenças que os definem.

A partir da leitura de Derrida (1978), Rayner afirma que em um diálogo, por exemplo, o mesmo Eu que fala também se configura como o Eu que escuta, nesse sentido, ele já constitui uma audiência de si mesmo. Entretanto, a autora lembra que tal relação de escuta mútua, quando acontece, está sempre determinada pelo contexto dos Eus. Nesse sentido, ser/estar audiência implica um ato que pode ser voluntário, porém sempre influenciado socialmente pelos papéis exercidos. Em outras palavras: "A minha escuta depende de semelhanças ou diferenças particulares: se eu já li os mesmos livros; se eu já escutei isso antes; se eu tenho uma dor de ouvido; se eu te vejo ou se te escuto pelo telefone; se eu suponho que 
somos parecidos ou diferentes" ${ }^{\prime \prime}$ (Rayner, 1993, p. 04).

Outro viés possível para pensar como nomear o pedestre que se tornará espectador na rua é a testemunha, tema recorrente nos estudos atuais da performance e que se manifesta como produtivo na investigação do sujeitopedestre que se torna espectador acidental. No estudo da pesquisadora australiana Caroline Wake (2009), a emergência do debate sobre a testemunha no teatro é associada ao aparecimento da testemunha nas humanidades, de um modo geral, e nos estudos sobre o trauma mais especificamente. Ela aponta que compreende o espectador-testemunha de duas formas; em uma ele estaria presente como testemunha do acontecimento e na outra como testemunha do relato, configurando-se como testemunha primária e secundária, respectivamente. Com base nos escritos teóricos de Jacques Rancière, a autora problematiza, igualmente, a noção de espectatorialidade (spectatorship) por ser uma atividade que não engloba o papel da testemunha. Nesse sentido, propõe o termo testemunhando (witnessing) como meio de contemplar amplamente o ato do espectador, porque the introduz outras camadas perceptivas, como as variações de temporalidade.

A teoria do testemunho incita uma ampliação do olhar acerca do pedestreespectador, pois considera diversos modos de participação no evento performativo, inserindo nuances de engajamento que consideram, inclusive, o olhar a distância, por exemplo, como um nível de atividade que não descarta o engajamento do sujeito. Ao analisar as condições de expectação do acidente, Wake (2009) detecta um paradoxo que complexifica e reafirma a necessidade de refletir acerca da recepção performativa.

Ainda que uma performance possa ser criada e ensaiada, possa ser planejada, possa ser prevista e possa (ao menos em algum âmbito) ser repetida - isto é o que faz disso uma performance. É o paradoxo impossível do "acidente ensaiado" que faz o testemunho no teatro tão impossível e ridículo, tão importante e milagroso9 (Wake, 2009, p. 15).

\footnotetext{
${ }^{8}$ My hearing depends on detailed differences or similarities: have I read the same books; have I heard this before; do I have an earache; do I see you or listen on the telephone; do I presume we are alike or different. (Tradução nossa)

9 Yet performance can be created and rehearsed, it can be planned, it can be predicted and it can (at least to some extent) be repeated - this is what makes it a performance. It is the impossible paradox of the 'rehearsed accident' that makes witnessing in the theatre so impossible and ridiculous, so important and miraculous. (Tradução nossa)
} 
Para contribuir com a tarefa de nomear o sujeito-pedestre, destaco a noção de participador, pensada pelo artista Hélio Oiticica - mais especificamente com a criação dos Parangolés. Oiticica estava movido pela intenção de afastar o espectador de atitudes artificiais, condicionadas a um monitoramento constante. O participador clama do público um grau de interação que ultrapassa a contemplação imóvel de telas e esculturas, porque o objeto artístico não se realiza se não houver participação. O corpo do espectador torna-se o núcleo central da obra de arte. A noção de espaço de exposição ganha nova roupagem nessa concepção passando a ser visto como ambiente por reforçar o deslocamento do espectador de um receptor para um agente da obra, capaz de exercer uma invenção criativa.

Acerca dessas mudanças, Oiticica descreveu o processo de alteração no status do participador quando assume a vestimenta da obra, mais tarde tornandose ele espectador do outro, ciclo que ele chamou de "vestir-assistir". "O 'vestir' [...] contrapõe-se ao 'assistir'. O vestir já em si se constitui numa totalidade vivencial da obra, pois ao desdobrá-la tendo como núcleo central o seu próprio corpo, o espectador como que já vivencia a transmutação espacial que aí se dá" (Oiticica, 1986, p. 71). A obra em Oiticica se atualiza na interação, conferindo não apenas ao sujeito a responsabilidade da atuação, mas ao todo espacial, incluindo os objetos estáticos enquanto produtores de significados. Sua invenção aproxima-se dessa discussão acerca do teatro performativo na cidade, uma vez que propõe uma vivência completa da arte e que, nesse processo, passa a ser participador.

Passear entre os termos apontados e suas abordagens distintas me faz perceber como cada um pode somar ao debate sobre o pedestre em situação de espectador na rua. A partir daqui, é possível apontar alguns aspectos de cada termo que permitem uma compreensão mais aguçada sobre o pedestreespectador. Primeiramente, é pertinente retomar o estudo de Néspoli (2015) que contribui de forma decisiva, na medida em que aponta os públicos endógeno e exógeno, contemplando sob perspectivas diferentes o pedestre casual que traz consigo a efemeridade em potencial. O espectador e a audiência, tal como colocados pelos autores mencionados, aproximam-se do pedestre quando fortalecem sua dimensão autônoma e contextual, por realizar no processo de 
leitura microescolhas e por atuarem como condição fronteiriça, onde o "Eu" que fala também se traduz no "Eu” que escuta (Rayner, 1993). Relação agravada pela visibilidade conferida ao espectador do espaço público quando, mesmo por trás de uma aparente invisibilidade, é assistido ao assistir. Já no contexto da noção de testemunha apresentado por Wake (2009), é possível acrescentar a testemunha primária de segundo grau que se configuraria quando o pedestre presencia à distância um acontecimento em que outros sujeitos estão interagindo. Por fim, o participador tal qual proposto por Oiticica concentra o espectador do teatro performativo em toda sua potencialidade de engajamento, sendo instância constitutiva para o próprio acontecimento se efetivar.

Compreendendo que cada noção carrega consigo sutis diferenças e semelhanças que possam haver entre os termos apresentados, opto por adotar o pedestre-espectador como termo a ser investido, segundo a perspectiva de que os pedestres se constituem enquanto público de modo coletivo e não hierárquico, conformando comunidades moventes e momentâneas.

\section{Performatividade e participação}

\footnotetext{
A antiga posição frente à obra de arte já não procede mais mesmo nas obras que hoje não exijam a participação do espectador, o que propõem não é uma contemplação transcendente, mas um 'estar' no mundo (Oiticica, 1986, p. 74).
}

Já na década de 1980, Oiticica reivindicava um posicionamento do leitor frente à obra de arte que extrapolasse a contemplação para dar lugar a um estado no mundo. Reivindicava esse novo posicionamento, porque compreendia que a própria obra de arte tinha passado por alterações em sua natureza que pediam modos outros de comunicar, partindo do princípio da construção realizada com o outro. Retomo: "Mesmo nas obras que não exijam a participação do espectador [...] o que propõem é um 'estar' no mundo". No contexto atual o que quer dizer estar envolvido e o que se configura como participação? Ao superarmos, supostamente, a relação dicotômica entre espectador ativo-passivo, ampliamos as possibilidades do pensamento e do olhar sobre o que configura engajamento e participação. Compreendendo que o espaço da cidade estimula o estabelecimento 
de relações fugazes, conformando a transitoriedade como via de regra, é premente refletir acerca dos aspectos que determinam engajamento e participação no teatro performativo urbano.

A teórica e ensaísta alemã Érika Fischer-Lichte (2008) comunica que a partir dos anos 1960 o teatro ocidental passou por um desvio performativo, cujas direções não o concebiam mais apenas como representação de um mundo ficcional que o público deveria observar, interpretar e compreender. A partir da leitura de Fischer-Lichte (2008), a pesquisadora Sílvia Fernandes (2011, p. 17) aponta que a performatividade "elude o escopo da teoria estética tradicional, pois resiste às demandas da hermenêutica de compreender a obra de arte", o que faz com que a participação do público vá além da tarefa de interpretar e produzir significado frente a uma performance. E "isso não quer dizer que, numa performance, não haja nada para o espectador interpretar, mas também não se pode dizer que as ações do artista performativo apenas signifiquem alguma coisa" (Fernandes, 2011, p. 17). Quando Fernandes chama atenção para a interpretação dos sentidos frente a uma cena como uma das possibilidades de experienciar o teatro, é possível perceber o apontamento de um campo perceptivo ampliado que, no entanto, não está dado, pois remete a um "estar no mundo", como nos lembra Oiticica.

Dentre os efeitos provocados pelo teatro performativo, Féral (2008, p. 204) aponta a ambiguidade, a pluralidade e o deslize dos sentidos da cena como recorrentes, atribuindo ao performer papel central no embaralhamento desses sentidos. Para a pesquisadora, acontecem no teatro performativo duas mudanças decisivas em relação ao teatro dramático; por seu caráter de exposição dos fatos, o processo ganha maior visibilidade do que o produto e a escrita cênica passa a ser desconstruída e caótica, diferenciando-se da linearidade habitual. Diante de tais mudanças apontadas, cujos deslocamentos no fazer implicam diretamente outros modos de ver, perceber e se relacionar com a obra de arte - chegando, em alguns casos, a confundir o limite entre manipulação e realidade - fala-se que a cena performativa apela a um maior grau de receptividade. Acerca dessa exigência em relação à figura do espectador, Féral (2008, p. 207) distingue dois tipos de relação que o mesmo pode estabelecer com o evento performativo: 
Quanto ao espectador, ele está, assim como o performer, situado na intimidade da ação, absorvido por seu imediatismo ou pelos riscos implicados no jogo (Le Dortoir, de Gilles Maheu). Mas ele pode também ficar no exterior da ação, gravar com frieza as ações que se desenrolam diante dele, mantendo um direito de olhar que permanece exterior, como ele o faz diante de certas performances. Sua maneira de percepção, portanto, nem sempre implica a absorção da obra. Ele pode também sustentar um direito de olhar que permanece exterior.

Ao não mencionar a adesão e a distância como tipos de relação excludentes, Féral (2008) amplia a dualidade (atividade/passividade) habitualmente atribuída à atividade da leitura, agregando ao pensamento sobre a recepção seu devido caráter tênue, de efemeridade e transitoriedade. Caráter que acredito ser potencializado a níveis específicos quando tratamos do acontecimento cênico realizado no espaço da cidade. Por todas as interferências que constituem a condição do urbano, o pedestre-espectador na rua passeia livremente entre a adesão e a distância apontadas pela autora. O acidental, por sua vez, não está ligado, necessariamente, a um ou outro modo de se relacionar com o espetáculo, porque ele diz respeito à condição do encontro com o evento, conferindo ao seu momento a possibilidade imediata de optar e transitar entre a adesão e a distância. A noção de testemunha primária de segundo grau, por exemplo, figura como central na ideia apontada por Féral, porque traz à luz camadas discretas do lugar da recepção que transitam pelos tipos de relação mencionados.

Solicitado então a se concentrar na materialidade das ações, efeito que resulta da ênfase na performatividade, a atenção do espectador se desloca entre a constante construção, desconstrução e reconstrução dos signos postos em cena. Para Féral (2008, p. 209), tal processo desemboca na instauração de uma "estética da presença", porque os envolvidos são constantemente solicitados a participarem das ações, tal como o performer. Diante dessa realidade, questiono: em que medida o fato dos espectadores serem solicitados a participar implica uma efetiva participação? Em outras palavras, ao exaltar o papel ativo do público, vê-se uma intensificação da sua atividade autoral, porém essa mudança "não altera a necessidade de um modo de adesão" (Néspoli, 2015, p. 57). Preocupação similar encontro na citação de Florian Malzacher ao discutir o chamado teatro participativo contemporâneo. 
Este é o verdadeiro 'pesadelo de participação' (para usar um termo de Markus Mießen): não o ser forçado a participar, mas ser forçado a uma participação forjada. Um envolvimento permanente (que basicamente significa que somos ativos apenas no sentido de que somos consumidores) ao qual não podemos fugir e que meramente nos impede de participar nos poderes reais. Passividade disfarçada de atividade. [...] Um teatro político contemporâneo tem de se colocar bem no meio desse dilema: não somente evitando uma participação falsa, mas ao mesmo tempo reivindicando a ideia da participação em si. [...] Tal envolvimento não tem de ocorrer necessariamente com o consenso das pessoas envolvidas. Ele também pode objetivar um confronto direto e pode fazer experimentos com falhas na comunicação e mesmo calúnias (Malzacher, 2016, s/p).

Com as palavras de Malzacher chego a pensar que o artista, ao colocar o espectador em jogo, deve aceitar que as possibilidades de sucesso ou fracasso são iminentes, resultantes de um evento que busca se aproximar cada vez mais intensamente da noção de real. O teatro que é pensado com o desejo de surgir/imergir da cidade, ou de fazer-se revelar a partir do que a mesma já tem em si de teatral, não pode escapar ao confronto da participação.

Faz-se necessária a retomada de determinados aspectos apontados sobre a performatividade que se relacionam em diversas direções com o contexto do debate. Levando em consideração a amplitude do campo de práticas e estudos da performance, bem como o traço da contaminação das linguagens que asseguram o terreno fértil da arte cênica contemporânea, verifico que alguns deslocamentos teóricos se deram, conformando pensamentos diversificados acerca do teatro. O teatro feito a partir de ocorrências performativas, então, permite/induz o espectador a um modo de percepção que apela para outras vias de absorção da obra. Se tomarmos a não-linearidade dos fatos como uma das características do teatro performativo (traço influenciado pelas construções dramatúrgicas contemporâneas), entenderemos que tal estrutura não acarreta uma perda, mas implica um outro modo de aproximação. 
Abrir as janelas e olhar o mundo: performance, a leitura do corpo pedestre-espectador

O corpo é o peso sentido na experiência que faço dos textos. Meu corpo é a materialização daquilo que me é próprio, realidade vivida e que determina minha relação com o mundo. Dotado de uma significação

incomparável, ele existe à imagem de meu ser: é ele que eu vivo, possuo e sou, para o melhor e para o pior

(Zumthor, 2007, p. 23).

A ideia de performance aqui recuperada não se reduz ao evento performático ou ao acontecimento entre performers. A ideia é despertada pelas leituras do filósofo Paul Zumthor, pelas reflexões acerca do evento coreográfico Estratégia ${ }^{10}$, do qual pude participar como performer, bem como pelas entrevistas com a diretora e pesquisadora em dança-teatro Zilá Muniz. Ao colocar-se no lugar do outro, daquele que é incumbido de apreciar, observar e decifrar a obra, Zumthor (2007) pretende investigar o "leitor lendo", sua ação em ação e o que esta contempla em termos de funcionamento, modalidades e efeitos. A partir de Zumthor, a ênfase recai sobre o "espectador assistindo", seu corpo durante o ato de leitura, nos casos aqui abordados mais especificamente da leitura do espaço e da cena que com ele acontece. Se compreendemos que a obra só acontece com o espectador e ele se encontra em um posicionamento ativo, então estamos analisando o corpo em performance, em estado poético, provocações que o Estratégia propõe quando enfatiza a produção de um evento compartilhado.

Zumthor (2007) distingue o processo de leitura em si, que de modo geral responde a uma decodificação em prol da obtenção de uma informação, de um outro processo de leitura que acontece em alguns casos. O autor defende que esses outros casos precisam ser ainda definidos, pois diversas variáveis influenciam o processo de leitura, tais como: o fato do texto possuir elementos não informativos e as ligações pessoais que o leitor estabelece (in)conscientemente com o material, gerando a poeticidade e o prazer da leitura. Conforme Zumthor (2007), ao invés de compreendermos o literário a partir da

10 O Estratégia surgiu do projeto de pesquisa Formação para Estratégia, desenvolvido pelo Ronda Grupo de Dança e Teatro, de outubro a dezembro de 2012, por meio do Fundo Municipal de Cultura de Florianópolis - Edital de Apoio às Culturas n. 003/2012. 
escrita, deveríamos nos concentrar na lógica inversa, ou seja, de que o literário se manifesta através da sua leitura, quando atualizada no corpo do leitor.

Ao recorrer à noção de performance, o autor reforça a necessidade de reintroduzir a consideração do corpo no estudo da obra. "Ora, o corpo (que existe enquanto relação, a cada momento recriado, do eu ao seu ser físico) é da ordem do indizivelmente pessoal" (Zumthor, 2007, p. 38). Nesse sentido, sua concepção de corpo está ligada diretamente ao âmbito da experiência pessoal, tornando desse modo impossível o ato de leitura apenas como decodificação. O corpo é reativado, remexido e reinserido enquanto agente dessa prática que por si só é carregada de comportamentos, posturas e estados. Sua singularidade irá, portanto, conferir poeticidade à leitura.

Em sua obra, Zumthor (2007) compartilha uma lembrança da infância em Paris, quando voltava do colégio para casa e assistia aos números dos cantores de rua. O autor conta que em algumas canções havia trechos que eram entoados em coro pelos espectadores; o texto das músicas podia ser comprado com algum dos camelôs que faziam parte da performance. No entanto, o destaque dado por Zumthor está no jogo que era estabelecido no momento presente, um estado impossível de ser reproduzido, mesmo quando ele levava o folhetim das músicas para casa e tentava cantá-las.

A narrativa exposta pelo autor traduz a ideia de performance como acontecimento acionado por corpos em ação de leitura no espaço e contribui de dois modos fundamentais com o presente texto, principalmente no que concerne ao compartilhamento das experiências enquanto espectadora: primeiro, ao enfatizar o caráter de irrepetibilidade do evento; segundo, ao traduzir a noção de performance desejada por ele, relacionando-a ao seu caráter de composição coletiva, ou seja, no qual todos os elementos participavam, mesmo que não intencionalmente. Ao observar atentamente sua descrição dos fatos, percebo que a participação do autor naquelas tardes não costumava ser acidental. Ao mesmo tempo, quando atento para sua ênfase no fato de que tudo compunha aquele acontecimento posso inferir que algo de acidental acompanhava a canção, escapava à delimitação de uma apresentação enquadrada numa determinada duração e localização espacial. O todo inapreensível, portanto, compunha o 
espetáculo e o espetáculo era o que atraía os corpos. Zumthor se deu conta de que ler o texto em casa não suscitava o mesmo efeito, o que confirmava a ideia de que a sua leitura presencial era singular, bem como o fato de conferir poeticidade àquele acontecimento composto de modo coletivo.

Na perspectiva de visualizar e apropriar-se do acontecimento poético, tal qual colocado por Zumthor (2007), porém sem provocar uma relação de causalidade, destaco o evento coreográfico, acontecimento e ação Estratégia, proposto pelo Ronda Grupo de Dança e Teatro ${ }^{11}$. O Estratégia se estrutura em blocos constituídos de jogos e brincadeiras que traçam um determinado trajeto na cidade. Um dos princípios-chave do seu fazer está na conexão com o ambiente, na capacidade de escuta e negociação, características básicas da prática improvisacional, seja em teatro ou dança.

Por se estruturar com base em jogos que devem, como regra, partir ou desmembrar-se do fluxo do ambiente, o Estratégia instaura um tipo de vínculo explicitamente participativo com o pedestre-espectador e uma comunicação poética, como defendeu Zumthor (2007), ao elucidá-la por sua tendência ou sua aptidão em gerar mais prazer do que informação. Quando questionada sobre os porquês da escolha do espaço público, Muniz (2015) explica que, primeiramente, havia um desejo de sair do confinamento da sala de ensaio, além da vontade de buscar espaços que trouxessem consigo a possibilidade de arriscar-se mais, onde o inesperado, o acaso, os acidentes e os tropeços fossem condições iminentes.

Por seu caráter de profundo vínculo com o ambiente, o Estratégia me conduz a uma reflexão acerca do lugar de participação do pedestre-espectador. Ao ser questionada sobre o melhor termo para descrever o pedestre que engata uma participação no Estratégia, Muniz (2015) opta pelo público, escolha que interpretamos como modo de contemplar uma maioria que representaria certa multiplicidade habitante da cidade. Na visão de Muniz (2015), do mesmo modo que o "simples" momento coletivo de pausa que dava o tom do início da ação já carregava certa teatralidade, o "simples" fato do pedestre observar aquele (não) movimento e enxergar ali algo de estranho, já the conferia o status de espectador, 
portanto de partícipe.

Segundo Fischer-Lichte (2008, p. 15), "a transformação do espectador em ator acontece quase automaticamente de acordo com a encenação, isso dificilmente é resultado de uma decisão consciente de parte do espectador" (Tradução nossa) ${ }^{12}$. No caso do Estratégia, existe uma linha tênue que perpassa essas transformações - entre pedestre-espectador e espectador-performer - visto que a maneira como o evento coreográfico se constrói parte das relações que surgem entre todos os elementos que o constituem. Sendo, portanto, no entre que os elementos se conectam para dar sentido, como numa dramaturgia relacional (Muniz, 2017). Aproximamos esse caráter de indissociabilidade que o evento performativo propõe, entre fazedores e fruidores, do entendimento de performance, tal como empregado por Zumthor (2007). Para o autor, a performance representa um termo antropológico e não histórico, relativo, por um lado, às condições de expressão, e por outro, da percepção. A performance designa, então, um modo de relação; refere-se a um momento tomado como presente significando, igualmente, a presença concreta de participantes implicados nesse ato de maneira imediata, tal como visualizamos acontecer no Estratégia.

Conferido de tal limite tênue de papéis, o Estratégia desenvolve seus trajetos, sobretudo provocando interações com a dinâmica dos espaços pelos quais dança. As estratégias para despertar tais interações surgem dos jogos que acontecem, alguns são parte do repertório e podem ser acionados, outros são inventados em negociação com o momento. Em obediência a uma das regras do evento, na qual os performers devem propor/interferir o mínimo e interagir o máximo com os fluxos do ambiente, os pedestres-espectadores são constantemente convidados à participação.

Durante a experiência como performer do Estratégia, o protagonismo do espectador em diversos jogos se mostrou um modo de relação eficaz e potente, porque criava um vínculo intenso e, ao mesmo tempo, "descompromissado" que se diferenciava daquele já vivenciado por mim como artista do teatro de rua.

12 The transformation of spectator into actor happened almost automatically as specified by the mise-enscene, it was hardly the result of a conscious decision on the part of the concerned spectator. (Tradução nossa) 
Entretanto, em certos momentos, tal protagonismo, que deveria ser conferido ao espaço como um todo, criava certa dependência com a interação do espectador, e vice-versa, acarretando situações em que se criavam armadilhas, pondo em xeque a própria continuação/duração do evento.

Um dos jogos propostos era o do cabo de guerra: em um dado momento, sem marcações prévias, o grupo se dividia em dois e começava a competição para ver quem tinha mais força. Os grupos, então, chamavam os pedestres que naquele espaço passavam para ajudar seu time. Dependendo da situação, do dia, bem como do espaço em que nós escolhíamos realizar o jogo, as pessoas ajudavam, riam, debochavam, apenas assistiam ou ignoravam. Caso ninguém se interessasse por participar, o jogo, necessariamente, deveria se transformar em outro. A esse caráter de vínculo explícito com o pedestre chamo de protagonismo.

Um dos pontos frisados por Muniz (2015), quando questionada sobre o espaço da produção de sentido no Estratégia, liga-se à questão do afeto. Por despertar no público o deslocamento por lugares de questionamento acerca da sua natureza, o acontecimento amplia as possibilidades de leitura do espectador, criando pequenas tensões nas noções de participação e apreciação. A relação de leitura e apreciação estabelecida com o pedestre-espectador no Estratégia se dava, então, através de um movimento oscilatório, entre a criação de imagens e a interação por jogos. Na dúvida pela escolha de rótulos que melhor adiram ao seu acontecimento, o Estratégia despertava em seus partícipes múltiplas "camadas de reações" (Muniz, 2015), onde o inesperado, o acidente e o imprevisível da cidade eram enfatizados. Nesse sentido, o aspecto da compreensão de um ou mais sentidos perde espaço se comparado à ênfase na ludicidade provocada pelo acontecimento, recuperando a questão da poeticidade da leitura que escapa à decodificação e obtenção de informação (Zumthor, 2007). A busca por um campo mais afetivo do que interpretativo é preocupação apontada por Muniz (2015) quando afirma que a narrativa do Estratégia não faz referência a nenhuma história especificamente, mas à própria trajetória da rua que é atualizada no momento da interação.

Para cada momento de atualização da improvisação existe a possibilidade emergente de surgir uma forma ou uma estrutura, porém tal forma ou estrutura se dissolve e se desloca em relação ao próximo 
momento e agrega nesse processo elementos com os quais está em tensão. Tal imprevisibilidade exige o estado de presença, de escuta, de prontidão e de disponibilidade que rigorosamente é fundamental entre os performers para que o Estratégia aconteça como um evento coreográfico. [...] Vale lembrar que Coreografia é um verbo - a atividade de organizar relações entre corpos. O que sugere que coreografia trabalha as relações entre corpos e que não se defina como uma prática feita pelo homem para o homem, e sim que é uma prática que se fundamenta em como o evento por si próprio se conecta com um 'milieu relacional que excede o ser humano ou em que o ser humano é mais ecologia do que indivíduo"13 (Muniz, 2017)

No Estratégia o performer atua, então, como agenciador dos impulsos que advêm do espaço. A ideia de percorrer a cidade com as "janelas abertas" diz respeito a um estado de prontidão, escuta e atenção que, segundo Muniz, irá assegurar a troca e o diálogo constante entre o coletivo e o meio. Estado que penso estender-se para o pedestre-espectador-performer, mesmo quando há uma mínima participação, pois a troca e o diálogo só poderão ser assegurados se alguma energia no âmbito da atenção e da disponibilidade for oferecida por parte do transeunte. A ideia de que o performer tem de estar, a todo momento, flexível e alerta para que o inesperado seja incorporado, desloca-o para um evento que busca ser mais acidentado do que acidental. Nesse sentido, é o próprio espaço que acidenta o performer, desafiando-o a criar novos acordos e propor outros jogos. O fio acidental no evento Estratégia, portanto, encontrava espaço na sua dinâmica de composição com o espaço da cidade, dialogando com seus fluxos.

\section{A urbanidade e outras vias de experimentação da cidade}

Aqui interessa a ideia de que há no texto que constitui o teatro uma parcela que não é conferida pelo autor, ator e mesmo espectador, mas pelo espaço. A partir daí o espaço urbano escreve a obra e inscreve na obra a sua marca, o seu traço, a sua urbanidade. Com base na relação de tensão que se alterna na vivência do sujeito urbano, Néspoli (2015) se inspira no estudo do filósofo Christoph Türcke para defender o quanto nossa percepção está atualmente afetada:

${ }^{13}$ Muniz cita a obra: Erin Manning. Always More Than One: Individuation's Dance. USA: Duke University Press, 2013. 
Em síntese, na argumentação de Türcke, os estímulos cotidianos tornaram-se 'de menos' para serem percebidos, enquanto a torrente de excitação midiática é 'demais' para ser absorvida, o que estaria levando a humanidade a uma espécie de anestesiamento da sensibilidade - termo usado aqui no sentido da percepção plena, aquela que articula sentidos, memória e afetos. Na sua visão, o organismo humano estaria sendo cada vez mais fortemente colocado 'na situação paradoxal de não ser mais capaz de transformar as sensações em percepção’ (Néspoli, 2015, p. 53).

No intuito de estabelecer diálogos diversificados, aproximo-me das práticas teatrais na rua do Coletivo Mapa Xilográfico, bem como dos escritos de Paola Jacques (2006). A partir da leitura de autores como Guy Debord e Michel de Certeau, Jacques (2006) apresenta dinâmicas de produção da cidade que proponham outros modos de conhecimento da mesma. Com a noção de deriva e suas relações de perda, erro e experimento, a experiência da cidade pode ser aproximada de uma cegueira "já que imagens e representações visuais não são mais prioritárias para a experiência” (Jacques, 2006, p. 119). O errante, como é chamado o sujeito que se permite derivar pelo espaço urbano, amplia seus sentidos corporais para vivenciar, a partir de falhas, perdas e encontros a experiência da cidade. A deriva é compreendida enquanto procedimento para a criação artística. Portanto, aproximo o errante daquele sujeito que, de certo modo, compartilha do evento, tal como o artista e o pedestre-espectador.

Conforme Carreira (2014, p. 216), ao considerarmos "o espaço inóspito e imprevisível que é a cidade, a hipótese do erro aparece como alternativa natural para a abertura do novo como estratégia de convivência fugaz com os transeuntes e seus fluxos através do uso das linguagens teatrais performativas". A hipótese do desencontro também aparece como natural do fluxo dos grandes centros urbanos. Nesse caso, o espaço da cidade se configura de modo a propiciar mais a dispersão do que a convergência, e o teatro, que com esse espaço se faz, encontra-se numa corrente de séries causais, na busca pelo olhar desatento do pedestre, na tentativa de fazê-lo fazer-se espectador por um momento.

Jacques (2006) observa três movimentos recorrentes e que estão interrelacionados na experiência errante do espaço urbano. O primeiro movimento aponta para o ato de se perder, o segundo para a lentidão e o terceiro para a 
corporeidade. Com relação ao primeiro, conforme Jacques (2006, p. 122) "podemos identificar três relações espaço-temporais (temporalidades) distintas: orientação, desorientação e reorientação". Tais movimentos integrados se configuram como resistência à proposta do urbanismo atual, pois caminham no contrafluxo de noções predominantes como orientação, aceleração e redução da experiência e presença física. Nesse sentido, com base na ideia de errância, pergunto: como as práticas performativas podem propor outros caminhos de vivência, construção e apropriação da cidade? Que cidade a experiência teatral performativa quer mostrar, evidenciar e quais são as tensões que provoca na relação do sujeito com seu espaço, ou seja, na noção de urbanidade?

Em diálogo direto com tais questões está a prática do Coletivo Mapa Xilográfico que surgiu na cidade de São Paulo em 2006 pela iniciativa dos artistas e educadores Diga Rios, Milene Ugliara e Tábata Costa. Suas primeiras ações consistiram no mapeamento de árvores cortadas de uma determinada região da cidade e na impressão de xilogravuras a partir dos troncos que restaram. Com inspiração direta nesta técnica de fazer gravuras em relevo sobre madeira, o Coletivo vem produzindo ao longo dos seus quatorze anos intervenções urbanas, principalmente, com base em imersões nos bairros centrais e periféricos de São Paulo. Quando questionada a respeito da constituição da obra nos trabalhos do coletivo, Ugliara (2017) afirmou:

Para nós a obra se organiza em torno do acontecimento, é um rito, um fluir de desejos e corpos coletivos em torno de um objetivo estético no espaço urbano: com um viés crítico político, irônico, cômico, mas sempre levando em conta a importância de fomentar o espaço público e tornálo público a partir do momento que nos apropriamos do espaço que é nosso, que fazemos desse lugar um uso múltiplo, não funcional, não produtivo para a economia da cidade, e sim com um grande potencial aglutinador, humanizador, transcendente e questionador das relações hierárquicas, opressivas, do encontro da relação homem-natura entre tantos outros.

Tocando na questão da autoria, indaguei o coletivo acerca dos disparadores para a constituição dos textos que guiam as criações. Geralmente o coletivo se concentra em uma determinada comunidade, bairro ou vila, onde passam a garimpar certos assuntos/temas próprios daquele lugar. Após determinado tempo 
de convivência, provocações acerca dos temas são levantadas pelos habitantes de cada localidade, impulsionando a geração de ações artísticas pelo coletivo. Os disparadores, então, passam a ser as percepções coletivas para determinado lugar, ou seja, a urbanidade passa a ser determinante enquanto traço do texto que será criado.

A questão da especulação imobiliária, bem como do processo de urbanização acelerado, pelo qual (ainda) vem passando a cidade de São Paulo, são temas que mobilizam, desde o início, a produção artística do coletivo no espaço urbano. A performance Gatunos S.A. explicita a indignação do coletivo frente ao processo de gentrificação sofrido pelas comunidades do distrito de Itaquera, quando começaram as desapropriações em prol da construção do Estádio de Futebol Itaquerão, zona leste do município de São Paulo, para a Copa do Mundo realizada no Brasil em 2014. Conforme Ugliara, a intervenção surgiu a partir de inquietações dos moradores da Vila Itororó, que estavam em vias de expulsão de suas casas. “A ação performática nesse caso é a própria realização da ação artística e a recepção se mistura à ação, pois os agentes da obra são os próprios habitantes das questões levantadas" (Ugliara, 2017).

Outra intervenção a destacar no repertório do coletivo é O Bloco do Pipa, realizada no ano de 2011 no bairro Santa Cecília. Os artistas do coletivo encontraram-se inconformados com uma prática sistemática implantada pela Prefeitura da cidade de São Paulo, que consistia na lavagem de calçadas, em especial da região central, efetivando um processo de higienização social, visto que lançava jatos de água de reuso sobre a população em situação de rua. O processo se dava sustentado por três estruturas: uma viatura da Guarda Civil Metropolitana, um caminhão de nome "cata-bagulho" e um caminhão pipa, para encerrar a limpeza. Claramente, os principais atingidos eram os moradores em situação de rua que viam seus pertences serem levados à medida que eram expulsos pelos jatos de água do caminhão que exibia o seguinte aviso: “Água não potável. Evitar contato com a pele e olhos". Desse contexto surge a criação do Bloco do Pipa, uma intervenção composta por um grupo de banhistas que acompanhavam o caminhão pipa em ação, trajados de pés de pato, óculos de mergulho, boias, pranchas dentre outros elementos que remetiam ao ato de banhar-se. 
$\mathrm{Na}$ madrugada anterior, lambe-lambes espalhados pelas pilastras do Minhocão relacionavam os agentes de limpeza urbana com o nome de um bairro elitista próximo dali, Higienópolis. A bateria intercalava sambas e marchas fúnebres, enquanto os corpos dos intervencionistas obstruíam a ação de expulsão. Ao longo do trajeto, um morador de rua integrou-se ao grupo, dançou, tocou, obstruiu a ação ao nosso lado. A rua é dele também (Rios; Ugliara, 2015, p. 69).

Ao ser questionada sobre a escolha do espaço público como principal atuação do Mapa, Ugliara (2015) reforça sua possibilidade coletiva como um diferencial para a produção artística, por ser um espaço fértil, onde a propriedade privada pode ser revista e os problemas da cidade discutidos em diálogo com quem a vivencia. Ao realizar trabalhos coletivos a partir da imersão no espaço urbano, o Mapa dialoga com a noção de urbanidade, interferindo direta e indiretamente na qualidade e nos modos como os sujeitos habitantes passam a se relacionar com o seu entorno, não apenas nos seus usos físicos, como também políticos. Nesse sentido, o coletivo intenciona ativar a experiência e aproximar-se, mesmo que de modo sutil, da autonomia como modo de gerar tensionamentos nos usos hegemônicos da cidade.

Tais ações artísticas se expressam através de diversas intervenções que, criadas coletivamente, encontram brechas no cotidiano e na história contada, revelando (des)usos, práticas e saberes dos espaços ocupados. A partir do contato com os habitantes das localidades ocupadas, o Coletivo confronta dados oficiais e não-oficiais, registra imagens e da materialidade do espaço ressalta sua dimensão histórica, mítica e política.

Ugliara (2015) ressalta que a intervenção urbana se traduz como uma prática potente para o Mapa Xilográfico porque ainda não está fechada em delimitações e classificações e, portanto, permite, através do seu fazer, inter-relacionar áreas e fazeres. A partir deste contexto, a divisão habitual entre artista e pedestreespectador torna-se complexa ao refletir sobre as intervenções do coletivo. Ugliara (2015) afirma que é uma tentativa constante não fazer a divisão entre quem é público e quem é interventor. Para tanto, os três integrantes buscam se diluir nas suas atuações, deixando de lado a relação do artista especialista para criar um ambiente de contaminação onde todos possam agir coletivamente em prol do acontecimento. Assim, coexistem nas intervenções muitos níveis de participação 
e engajamento que extrapolam o momento da ação e a própria ideia de assistir.

O caráter acidental em coletivos como o Mapa Xilográfico encontra-se tanto no fato de que o grupo trabalha com imersões nos espaços para ressaltar deles o que está camuflado de algum modo, quanto no próprio uso inusitado que os trabalhos conferem aos locais que não são convencionalmente ocupados por manifestações de cunho artístico.

Para nós a análise da recepção dessas ações poéticas na cidade é o quanto o acontecimento gerou uma apropriação dos moradores que de certa forma formaram conosco um coletivo, o que significou de fortalecimento das lutas, dos vínculos, da percepção da cidade, das percepções de fortalecimento pessoal diante das fragmentações cotidianas, enfim, tentamos captar como a arte se relaciona como um veículo de potência, afirmação e coletividade nas diversas possibilidades do fazer artístico que encontramos (Ugliara, 2017).

A partir da resposta de Ugliara, me pergunto: com que instrumentos podemos de fato lançar um olhar sobre as transformações provocadas pelo coletivo? 0 efeito das ações realizadas pelas e lançadas para as comunidades/vilas/bairros e seus entornos pode ser refletido a partir da ideia de urbanidade, quando compreendida a longo prazo, porque a noção de (re)apropriação do uso espacial se dá à medida em que se instaura uma continuidade das práticas.

Reflito acerca da cidade enquanto espaço de conflito de interesses, ideias e práticas, configurando-se num campo problemático, de constante tensão entre as ordens afetiva, mercadológica e conflituosa (Jacques, 2006). A arte que nela se propõe traz consigo, portanto, a infinidade de possibilidades contidas e supostas no espaço, podendo, desse modo, potencializar outros modos de estar, conviver e agir no mundo. A ideia de corpografia (Jacques, 2006) associada à experiência do pedestre-espectador apresenta a possibilidade de (re)inscrever a memória urbana no corpo, negociando com os conflitos historicamente instituídos. O próprio Coletivo Mapa Xilográfico trabalha intensamente nesse sentido, desde quando em seus passos iniciais recupera histórias e memórias de árvores apagadas em bairros espalhados pela cidade de São Paulo.

A partir dos relatos compartilhados e noções teóricas apontadas é possível chegar ao entendimento de que o pedestre-espectador, em contato com 
manifestações cênicas de cunho performativo, realiza simultaneamente uma leitura e uma escrita do/no/com o espaço urbano. Cada configuração espacial intencionalmente proposta pelos grupos e coletivos trazidos deixa ver uma possibilidade de abordar a cidade, escolha que convida a certos modos de participação no evento, porém que não garante um comportamento específico. A ideia de performance, conforme Zumthor, possibilita pensar acerca do corpo pedestre-espectador em seu estado de leitura singular, corpo este que confere poesia à cidade, poeticidade.

\section{Referências}

ABREU, Kil. Observatório do chão para cenas de rua. Teatro Jornal: leituras de cena. 2016. Disponível em: http://teatrojornal.com.br/2016/11/observatorio-do-chaopara-cenas-de-rua/. Acesso em: 18 ago. 2017.

Campos, Cecília Lauritzen Jácome. Lugares da experiência na cena performativa recente: uma problematização acerca do espectador e seu exercício crítico de leitura/produção. Revista Aspas, 6(1), 62-72, 2016. Disponível em: https://www.revistas.usp.br/aspas/article/view/113287

CARREIRA, André. O teatro de invasão de espaço urbano e a ideia de eficácia. In: RAITER, Luana. BENNATON, Pedro. Poética do ERRO: registros. Itha do Desterro: ERRO Grupo de Teatro, p. 217-242, 2014.

DERRIDA, Jacques. Writing and Difference. Trad. Alan Bass. Chicago: The University of Chicago Press, 1978.

FÉRAL, Josette. Por uma poética da performatividade: o teatro performativo. Sala Preta, São Paulo, no 8, p. 197-210, 2008. Tradução: Lígia Borges.

FERNANDES, Sílvia. Teatralidade e performatividade na cena contemporânea. Repertório, Salvador, v. 1, n. 16, p.11-23, jun. 2011.

FISCHER-LICHTE, Erika. The transformative power of performance. London and New York: Routledge, 2008.

JACQUES, Paola Berenstein. Elogio aos Errantes: a arte de se perder na cidade. In: JEUDY, Henri Pierre. JACQUES, Paola Berenstein. Corpos e cenários urbanos: Territórios urbanos e políticas culturais. Salvador: EDUFBA; PPG-AU/FAUFBA, p. 117139. 2006.

MALZACHER, Florian. Não somente um espelho. Observatório dos Festivais. 2016. Disponível em: http://www.festivais.org.br/single-post/2016/11/12/ARTIGO- 
N\%C3\%A3o-somente-um-espelho. Acesso em: 02 out. 2017.

MUNIZ, Zilá. Entrevista concedida a Cecília Lauritzen Jácome Campos. 11 de novembro de 2015, Biblioteca Universitária da UDESC, Florianópolis. Não publicada.

MUNIZ, Zilá. Entrevista concedida a Cecília Lauritzen Jácome Campos. Via e-mail. 03 de agosto de 2017. Não publicada.

NÉSPOLI, Elizabeth Maria. Teatro da Vertigem: Construção Poética e Recepção. Estudo do campo de tensão que se instaura no encontro da proposição artística com seus receptores. 586 f. Tese (Doutorado) - Escola de Comunicações e Artes, Universidade de São Paulo, São Paulo, 2015.

OITICICA, Hélio. Aspiro ao Grande Labirinto. Rio de Janeiro: Rocco, 1986.

PAVIS, Patrice. Dicionário de Teatro. São Paulo: Perspectiva, 2007.

RAYNER, Alice. The audience: subjectivity, community and the ethics of listening. In: Journal of dramatic theory and criticism. p. 3-24. 1993.

RIOS, Diogo; UGLIARA, Milene Valentir. Intervenção Urbana e desespetacularização: a experiência do Coletivo Mapa Xilográfico. Rebento, São Paulo, n. 05, p. 62-73, 2015.

UGLIARA, Milene Valentir. Entrevista concedida a Cecília Lauritzen Jácome Campos. Via Skype. 17 de novembro de 2015. Não publicada.

UGLIARA, Milene Valentir. Entrevista concedida a Cecilia Lauritzen Jácome Campos. Via e-mail. 14 de julho de 2017. Não publicada.

WAKE, Caroline. The Accident and the Account: Towards a Taxonomy of Spectatorial Witness in Theatre and Performance Studies. In: Performance Paradigm. 5.1. 2009.

ZUMTHOR, Paul. Performance, recepção, leitura. São Paulo: Cosac Naify, 2007.

Recebido em: 23/03/2021

Aprovado em: 11/06/2021 